\title{
Efficacy of a Pectin-Lecithin Complex for Treatment and Prevention of Gastric Ulcers in Horses
}

Macarena Sanz, DVM, MS, DACVIM*; Adrienne Viljoen, BVSc; Montague N Saulez, BVSc, MS, PhD, DACVIM; Steve Olorunju, PhD; Frank M Andrews, DVM, MS, DACVIM.

From the Department of Companion Animal Clinical Studies (Sanz, Saulez, Viljoen), Faculty of Veterinary Science, University of Pretoria, Onderstepoort 0110, South Africa, The Biostatistics Unit, Medical Research Council of South Africa (Olorunju), Pretoria 0001, South Africa and The Department of Veterinary Clinical Sciences (Andrews), School of Veterinary Medicine, Louisiana State University, Louisiana 70803, USA. Dr. Sanz present address is Maxwell H. Gluck Equine Research Center, Department of Veterinary Science, University of Kentucky, Lexington, KY, 40546, USA.

Dr. Saulez present address is Drakenstein Veterinary Clinic, Western Cape, 7599, South Africa

*email for correspondence: macarena.sanz@uky.edu

The objective of this study was to evaluate the effect of a commercial feed supplement containing pectin-lecithin on squamous mucosa ulceration in horses exposed to an experimental ulceration model. Five mares were treated while 5 mares were control for this cross over, blinded study. The mares were fed concentrates and hay and were stabled most of the day for a period of 4 weeks. The pectin-lecithin complex fed for the duration of the study on the treated group. At the end of a 4-week period, all mares underwent a 7-day alternating feed-deprivation (week 5). The study was repeated again after a 4-week washout period. Gastroscopy was performed on days 1, 28 and 35 of the study and was digitally recorded. Independent evaluation of the recordings and scoring of the lesions using the EGUS, severity and number scores were performed by three veterinarians. The prevalence and severity of squamous ulcers significantly increased after intermittent feed deprivation 
$(p<0.001)$. No significant effect of the treatment was observed $(p>0.05)$. In this study, the addition of a commercially available pectin-lecithin complex to the feed of horses for 5 weeks did not prevent or minimize the risk for gastric ulceration of the squamous mucosa.

Ulceration of the squamous (non glandular) mucosa of the stomach is common and a major health concern in horses. The prevalence of gastric ulceration using gastroscopy in adult horses is greater than $80 \%$ in Thoroughbred racehorses (Murray and others 1996; Vatistas and others 1999), ranges between 52-87\% in Standardbreds racehorses (Cate and others 2012; Rabuffo and others 2002), between 57-93\% in endurance horses (Nieto and others 2004; Tamzali and others 2011) and affects 58\% of show horses in training (McClure and others 1999). These ulcers may heal spontaneously (MacAllister and Sangiah 1993; Venner and others 1999); however this is uncommon in horses that are either in training or racing and medical therapy is frequently required (Andrews F M 1999; Endo and others 2012). Treatment with pharmacologic agents is expensive, must be administered once or multiple times daily for extended time. (Andrews F M 1999; Buchanan and Andrews 2003). In addition, such products are prescription-only thus have limited availability. Therefore, dietary supplements that possess anti-ulcerogenic properties are highly desirable to prevent squamous mucosa ulceration in horses that are at risk (Cargile and others 2004; Frank and others 2005; Huff and others 2012).

Multiple feed supplements are currently available to horse owners; however few have been scientifically evaluated (Cargile and others 2004; Frank and others 2005; Huff and others 2012; Stowers and others 2013). A commercial product containing a pectin-lecithin complex $^{\mathrm{a}}$ is available in South Africa and it is widely used for treatment of gastric ulcers in horses. Reports using this product are conflicting (Ferrucci and others 2003; Murray and Grady 2002; Venner and others 1999). Lecithin is a phospholipid that reduces surface tension 
at the air-water interface (Hills 1982; Kidd 2002). Natural phospholipids are often used as feed additives and have a role in gastric mucosal defense against the damaging effects of luminal acid in dogs (Swarm and others 1987). Exogenous phospholipids such as lecithin may be clinically useful in prevention of equine gastric ulcers (Ethell and others 2000). Pectins are found in numerous fruits, tubers and stem plants; and are rendered into a gel when exposed to an acidic environment (Kidd 2002). Pectins may bind to bile acids of the gastroduodenal juice and prevent them from having deleterious effects on gastric mucosa (Venner and others 1999).

The purpose of this study was to evaluate whether a commercially available feed supplement containing a pectin-lecithin complex ${ }^{\mathrm{a}}$ would prevent squamous mucosa ulceration in horses exposed to model known to induce ulceration of that specific portion of the gastric mucosa. We hypothesized that addition of the feed supplement to the diet as instructed by the product's label would prevent or significantly decrease the number and severity of squamous mucosa ulceration.

\section{Materials and methods}

Ten healthy mares were selected for the study. The mares were determined to be healthy based on physical examination, complete blood cell count (CBC) and fibrinogen concentration. Each mare was individually kept in a $3 \times 3 \mathrm{~m}$ stall for 48 hours prior to and during the treatment periods and was allowed access to a dirt pen for 2 hours of exercise daily. During the washout period, mares were housed in a pasture.

The ten mares were randomly allocated to 2 groups. A crossover design was used with two, 5-week treatment periods separated by a 4-week washout period (14 weeks total). The mares were fed add libitum teff hay and $1 \%$ of their body weight of a commercially available concentrate ${ }^{\mathrm{b}}$ (week 1 to 4 ). The concentrates were incrementally introduced to the 
diet by $25 \%$ every 48 hours as it was previously described (Frank and others 2005). The hay and concentrates were fed twice a day (morning and afternoon). In addition, the treatment group was fed the pectin-lecithin complex in the morning as indicated on the product's label $(50 \mathrm{~g} / 100 \mathrm{~kg}$ of body weight once a day).

During week 5, the mares in both groups were deprived of feed for $24 \mathrm{~h}$ (to a total of 96 cumulative hours) and fed as normal on alternative days (intermittent feed deprivation period) according to a previous model (Frank and others 2005; Murray 1994; Murray and Eichorn 1996). Feed deprivation was achieved by completely removing all source of food from the stable. During the feed deprivation period, the treatment group received the pectinlecithin supplement ${ }^{\mathrm{a}}$ once a day in the morning. A similar volume of concentrates $(50 \mathrm{~g} / 100 \mathrm{~kg}$ of body weight) was fed at the same time to the control mares. For the second phase of the study, after the 4-week washout period, mares that received the treatment in the first period of the study served as control group and vice versa (cross over design). Mares were observed daily for any signs of colic.

Gastroscopy was performed under sedation (Romifidine ${ }^{\mathrm{c}}, 0.04 \mathrm{mg} / \mathrm{kg}$, IV) using a $3 \mathrm{~m}$ endoscope $^{\mathrm{d}}$ at the start of the study (day 1), after 4 weeks of treatment (day 28) and at the end of the intermittent feed deprivation period (day 35). Feed was withheld for 16-18 hours and water for 3-4 hours prior to gastroscopy. All gastroscopies were performed in the morning by a single evaluator (MS) and body weight was recorded. The nonglandular mucosa (fundus ventriculi), the glandular mucosa (corpus ventriculi) and the pylorus were evaluated after air insufflation of the stomach. All video-gastroscopies were recorded ${ }^{\mathrm{e}}$. The recordings were independently evaluated in a mixed, randomized order at the end of the project separately by three veterinarians, masked to the treatment given. Ulcers present in the squamous mucosa were scored by number (scale 0 to 4 ), severity (scale 0 to 5), and overall appearance (scale 0 
to 4) using two previously described scoring systems (Andrews and others 1999; MacAllister and others 1997) (Tables 1-3).

Table 1 - Description of the Lesion Number Score system used to score gastric ulceration

\begin{tabular}{|l|l|}
\hline Score & Description \\
\hline 0 & No lesions \\
\hline 1 & $1-2$ localized lesions \\
\hline 2 & $3-5$ localized lesions \\
\hline 3 & $6-10$ localized lesions \\
\hline 4 & $>10$ lesions or diffuse (or very large) lesions \\
\hline
\end{tabular}

MacAllister, C.G., Andrews, F.M., Deegan, E., Ruoff, W. and Olovson, S.G. (1997) A scoring system for gastric ulcers in the horse. Equine Vet $J \mathbf{2 9}, 430-433$.

Table 2 - Description of the Lesion Severity Score system used to score gastric ulceration

\begin{tabular}{|l|l|}
\hline Score & Description \\
\hline 0 & No lesion \\
\hline 1 & Appears superficial (only mucosa missing) \\
\hline 2 & Deeper structures involved (>depth than 1) \\
\hline 3 & Multiple lesions and variable severity (1,2 and/or 4) \\
\hline 4 & $\begin{array}{l}\text { Deeper structures involved (>depth than 1)0 and active (hyperemic and/or darkened lesion } \\
\text { crater) }\end{array}$ \\
\hline 5 & Same as 4 plus hemorrhage or adherent blood clot \\
\hline
\end{tabular}

MacAllister, C.G., Andrews, F.M., Deegan, E., Ruoff, W. and Olovson, S.G. (1997) A scoring system for gastric ulcers in the horse. Equine Vet J 29, 430-433.

Table 3 - Description of the EGUS Score system used to score gastric ulceration

\begin{tabular}{|l|l|}
\hline Score & Description \\
\hline 0 & The epithelium is intact, and there is no appearance of hyperemia or hyperkeratosis \\
\hline 1 & The mucosa is intact, but there are areas of reddening or hyperkeratosis \\
\hline 2 & Small, single or multifocal lesions \\
\hline 3 & Large, single or multifocal lesions or extensive superficial lesions \\
\hline 4 & Extensive lesions with areas of apparent deep ulceration \\
\hline
\end{tabular}

Andrews F, Bernard W, Byars D. (1999) Recommendations for the diagnosis and treatment of equine gastric ulcer syndrome (EGUS). Equine Gastric Ulcer Council. Equine Veterinary Education 1999;11:262-272.

The protocol was approved by the University of Pretoria Animal Use and Care Committee (Protocol number V019-09).

Statistical analysis - T-test was used to compare body weight results (kg). Pairwise comparison (treatment $v s$. non treatment) of lesion scores on days 1 and 28 were assessed for differences between groups using the Wilcoxon signed rank test. Mann U Whitney was used to compare lesions scores on day $35 .{ }^{\mathrm{f}}$ Values of $\mathrm{p}<0.05$ were considered significant. 


\section{Results}

The median age of the mares was 4 years (range 3 to 6 years). The mean \pm (s.d) body weight before entering the study was $329 \mathrm{~kg}( \pm 16.4 \mathrm{~kg})$ and no differences were observed between groups ( $\mathrm{p}>0.05)$. Body weight did not change during the study and no significant effect of treatment was observed $(\mathrm{p}=0.986)$.

Mild ulceration of the squamous mucosa was observed in all the mares on day 1 of each study period (Table 4). However, before inclusion into the study, all the mares had equal ulcer scores $(p>0.05)$. There was no significant effect of treatment on number $(p=0.266)$, severity $(\mathrm{p}=0.171)$ or EGUS ( $\mathrm{p}=0.878)$ scores on day 28 of the study (Table 4$)$. Significantly higher number, severity and EGUS ( $p<0.0005)$ scores were recorded on day 35 (Table 4). There was no significant effect of treatment on number $(\mathrm{p}=0.946)$, severity $(\mathrm{p}=0.547)$ or EGUS ( $\mathrm{p}=0.341)$ scores on day 35 (Table 4).

Table 4 - Lesion Number, Severity and EGUS scores observed on days 1, 28 and 35 of the study. The values represent the mean scores (SD) of the 3 observers for the 2 study periods.

\begin{tabular}{|l|c|c|c|c|c|c|}
\cline { 2 - 7 } \multicolumn{1}{c|}{} & \multicolumn{2}{c|}{ Lesion Number Score } & \multicolumn{2}{c|}{ Lesion Severity Score } & \multicolumn{2}{c|}{ EGUS Score } \\
\cline { 2 - 7 } & Treatment & Control & Treatment & Control & Treatment & Control \\
\hline Day 1 & $0.93^{*}(1.17)$ & $1.20^{*}(1.30)$ & $0.80^{*}(1.0)$ & $0.90^{*}(0.96)$ & $0.90^{*}(0.88)$ & $0.93^{*}(0.83)$ \\
\hline Day 28 & $0.70^{*}(0.84)$ & $0.93^{*}(1.05)$ & $0.70^{*}(0.88)$ & $1.07^{*}(1.14)$ & $0.97^{*}(0.93)$ & $1.00^{*}(0.95)$ \\
\hline Day 35 & $2.63^{\dagger}(1.14)$ & $2.70^{\dagger}(1.29)$ & $2.50^{\dagger}(1.20)$ & $2.30^{\dagger}(1.26)$ & $2.07^{\dagger}(0.91)$ & $1.87^{\dagger}(1.04)$ \\
\hline
\end{tabular}

Based on pairwise comparisons by day for treatment vs control group. Values without superscripts in common are significantly different $(\mathrm{P}<0.05)$.

\section{Discussion}

The results of this study support those of Murray et al (2002). Our study was of similar design; however the treatment period used here followed that recommended by the manufacturer (28 days) instead of the 7 day period previously used (Murray and Grady 2002). A beneficial effect of the same product on gastric ulceration has been previously reported in clinical cases (Ferrucci and others 2003; Venner and others 1999). Lack of randomization during treatment allocation and blindness of the evaluators to the treatment 
given may account for some of the disparities observed. In addition, because such studies were done under clinical circumstances, changes in management may have had an impact in the outcome. Both authors concluded that a longer treatment period might be more beneficial as complete resolution of the ulcers was not observed in either study (Ferrucci and others 2003; Venner and others 1999).

In the study reported here, ulceration of the squamous mucosa was artificially induced by intermittent feed deprivation as previously described (Frank and others 2005; Murray 1994; Murray and Grady 2002). Even though this is an artificial way to induce gastric ulceration, it provides an experimental standardized model without the variations that may occur when using clinical cases.

One of the limitations of this study was the presence of mild ulceration (scores $<1.2$ using all 3 scoring systems) of the squamous mucosa on the mares at the beginning of each study period (day1). This finding was not unexpected as high incidence of squamous mucosa ulceration has been reported in broodmares out in pasture (le Jeune and others 2009). In addition, the mares used in this study were young which may have predisposed them to ulceration (Peretich and others 2009). The lack of improvement of these after 28 days of supplementation was unexpected as the ulcers were graded as mild by all the evaluators. Supplementation with the pectin-lecithin complex may have been more beneficial if administered at midnight as gastric $\mathrm{pH}$ has been shown to decrease from $01 \mathrm{~h} 00$ to $09 \mathrm{~h} 00$ (Husted and others 2009; Husted and others 2008); however such practice does not reflect routine horse management. Further studies are required to assess whether the pectin-lecithin complex $^{\mathrm{a}}$ has antiulcerogenic properties if it is administered at a higher volume or frequency.

A 4-week washout period was selected to avoid potential carryover effects and to allow healing of the gastric ulcers (Murray and Grady 2002; Murray and others 2001). Complete resolution of the squamous ulceration was not achieved after the washout period, 
suggesting that a longer wash out period may have been more beneficial. It is important to note that there were no differences between the scores assigned to each group on each different period, hence a carry over effect can be ruled out. Ideally, omeprazole ${ }^{\mathrm{g}}$ should have been given before the study and during the washout period to minimize presence of squamous ulceration at the beginning of each period. Unfortunately, at the time of the study, no formulations of omeprazole were available for the use in horses in the country. The use of $\mathrm{H}_{2}$ blockers was evaluated; however efficacy of $\mathrm{H}_{2}$ blockers to induce complete healing of ulceration has been shown to be variable (Holland and others 1997; Murray and Eichorn 1996; Orsini and others 2003).

Despite the lack of exercise and the concentrates fed to the mares for the 28-day study period, their body weight did not change during the study. The same electronic scale, which is used daily at our hospital, was used throughout out the study. The mares were weighed at arrival to the hospital every morning before gastroscopies were performed, after feed had been withheld for a period of 18 hours, which could have influenced their body weight. In addition, the feed deprivation period may have played a roll. Energy levels of the diet were not measured in this study; there is a possibility that the diet did not provide excessive calories.

There were no significant differences in the ulcer scores between mares that received the treatment and mares that didn't. Based on these findings, we conclude that, under the conditions of the study reported here, administration of the feed supplement ${ }^{\mathrm{a}}$ was ineffective at preventing squamous gastric ulceration. This is consistent with the findings reported by others (Murray and Grady 2002). There is a possibility that the model used in this study was too severe for the product; however resolution or improvement of the naturally occurring, mild, gastric ulceration present at the beginning of the study after 28 days of treatment was not observed either. 
Acknowledgments: The authors would like to thank Dr Nicolas Villarino for his help with the statistical analysis of this study.

\section{Footnotes}

a. $\quad$ Pronutrin $®$, Boehringer Ingelheim, Ingelheim, Germany

b. Epol, Division of Rainbow Farms (Pty) Ltd, Johannesburg, South Africa

c. Sedivet@, Boehringer Ingelheim, Ingelheim, Germany

d. Olympus Medical System Corporation, Tokyo, Japan

e. HDRW 720 DVD recorder, Koninklijke Philips Electronics N.V

f. StataCorp 2009. Stata Release 11. Statisitcal Software. College Station, TX:

StataCorp LP, USA

g. GastroGard®. Merial Limited. Duluth, GA, USA.

\section{References}

ANDREWS, F., BERNARD, W. \& BYARS, D. (1999) Recommendations for the diagnosis and treatment of equine gastric ulcer syndrome (EGUS)Equine Gastric Ulcer Council. Equine Veterinary Education 11, 262-272

ANDREWS F M, S. R. L., BERNARD W, HUGHES F E, HOLSTE J E, DAURIO C P, ALVA R COX J L (1999) Efficacy of omeprazole paste in the treatment and prevention of gastric ulcers in horses. Equine Vet J Suppl 29, 81-86

BUCHANAN, B. R. \& ANDREWS, F. M. (2003) Treatment and prevention of equine gastric ulcer syndrome. Vet Clin North Am Equine Pract 19, 575-597

CARGILE, J. L., BURROW, J. A., KIM, I., COHEN, N. D. \& MERRITT, A. M. (2004)

Effect of dietary corn oil supplementation on equine gastric fluid acid, sodium, and prostaglandin E2 content before and during pentagastrin infusion. J Vet Intern Med 18, 545549

CATE, R., NIELSEN, B., SPOONER, H., CONNOR-ROBINSON, C. \& SCHOTT, H. (2012) Prevalence of gastric ulcers and relationship to other parameters in Standardbred racehorses. Comparative Exercise Physiology 8, 47-51

ENDO, Y., TSUCHIYA, T., SATO, F., MURASE, H., OMURA, T., KOROSUE, K., NAMBO, Y., ISHINAW, M. \& WAKUI, Y. (2012) Efficacy of omeprazole paste in the prevention of gastric ulcers in 2 years old Thoroughbreds. $\mathrm{j}$ vet med sci 74, 1079-1081 ETHELL, M., HODGSON, D. \& HILLS, B. (2000) Evidence for surfactant contributing to the gastric mucosal barrier of the horse. Equine Vet J 6, 470-474 
FERRUCCI, F., ZUCCA, E., CROCI, C., DI FABIO, V. \& FERRO, E. (2003) Treatment of gastric ulceration in 10 standardbred racehorses with a pectin-lecithin complex. Vet Rec 152, 679-681

FRANK, N., ANDREWS, F. M., ELLIOTT, S. B. \& LEW, J. (2005) Effects of dietary oils on the development of gastric ulcers in mares. Am J Vet Res 66, 2006-2011

HILLS, B. (1982) Water repellency induced by pulmonary surfactants. J Physiol, 175-186 HOLLAND, P. S., RUOFF, W. W., BRUMBAUGH, G. W. \& BROWN, S. A. (1997) Plasma pharmacokinetics of ranitidine $\mathrm{HCl}$ in adult horses. J Vet Pharmacol Ther 20, 145152

HUFF, N. K., AUER, A. D., GARZA, F., JR., KEOWEN, M. L., KEARNEY, M. T., MCMULLIN, R. B. \& ANDREWS, F. M. (2012) Effect of sea buckthorn berries and pulp in a liquid emulsion on gastric ulcer scores and gastric juice $\mathrm{pH}$ in horses. J Vet Intern Med 26, 1186-1191

HUSTED, L., SANCHEZ, L. C., BAPTISTE, K. E. \& OLSEN, S. N. (2009) Effect of a feed/fast protocol on $\mathrm{pH}$ in the proximal equine stomach. Equine Vet J 41, 658-662 HUSTED, L., SANCHEZ, L. C., OLSEN, S. N., BAPTISTE, K. E. \& MERRITT, A. M. (2008) Effect of paddock vs. stall housing on 24 hour gastric $\mathrm{pH}$ within the proximal and ventral equine stomach. Equine Vet J 40, 337-341

KIDD, P. (2002) Phosphoipids: Versatile Nutraceuticals for Functional Foods. Functional Foods and Nutraceuticals

LE JEUNE, S. S., NIETO, J. E., DECHANT, J. E. \& SNYDER, J. R. (2009) Prevalence of gastric ulcers in Thoroughbred broodmares in pasture: a preliminary report. Vet J 181, 251255

MACALLISTER, C. G., ANDREWS, F. M., DEEGAN, E., RUOFF, W. \& OLOVSON, S. G. (1997) A scoring system for gastric ulcers in the horse. Equine Vet J 29, 430-433

MACALLISTER, C. G. \& SANGIAH, S. (1993) Effect of ranitidine on healing of experimentally induced gastric ulcers in ponies. Am J Vet Res 54, 1103-1107

MCCLURE, S. R., GLICKMAN, L. T. \& GLICKMAN, N. W. (1999) Prevalence of gastric ulcers in show horses. J Am Vet Med Assoc 215, 1130-1133

MURRAY, M. J. (1994) Equine model of inducing ulceration in alimentary squamous epithelial mucosa. Dig Dis Sci 39, 2530-2535

MURRAY, M. J. \& EICHORN, E. S. (1996) Effects of intermittent feed deprivation, intermittent feed deprivation with ranitidine administration, and stall confinement with ad libitum access to hay on gastric ulceration in horses. Am J Vet Res 57, 1599-1603 MURRAY, M. J. \& GRADY, T. C. (2002) The effect of a pectin-lecithin complex on prevention of gastric mucosal lesions induced by feed deprivation in ponies. Equine Vet J 34, 195-198

MURRAY, M. J., NOUT, Y. S. \& WARD, D. L. (2001) Endoscopic findings of the gastric antrum and pylorus in horses: 162 cases (1996-2000). J Vet Intern Med 15, 401-406 MURRAY, M. J., SCHUSSER, G. F., PIPERS, F. S. \& GROSS, S. J. (1996) Factors associated with gastric lesions in thoroughbred racehorses. Equine Vet J 28, 368-374 NIETO, J. E., SNYDER, J. R., BELDOMENICO, P., ALEMAN, M., KERR, J. W. \& SPIER, S. J. (2004) Prevalence of gastric ulcers in endurance horses--a preliminary report. Vet J 167, 33-37

ORSINI, J. A., HADDOCK, M., STINE, L., SULLIVAN, E. K., RABUFFO, T. S. \& SMITH, G. (2003) Odds of moderate or severe gastric ulceration in racehorses receiving antiulcer medications. J Am Vet Med Assoc 223, 336-339

PERETICH, A., ABBOTT, L., ANDREWS, F. \& DHAR, M. (2009) Age-dependent regulation of sodium-potassium adenosinetriphosphatase and sodium-hydrogen exchanger mRNAs in equine nonglandular mucosa. Am J Vet Res 70, 1124-1128 
RABUFFO, T. S., ORSINI, J. A., SULlIVAN, E., ENGILES, J., NORMAN, T. \&

BOSTON, R. (2002) Associations between age or sex and prevalence of gastric ulceration in Standardbred racehorses in training. J Am Vet Med Assoc 221, 1156-1159

STOWERS, N., WALDRON, L., PRYOR, I., HILL, S. \& O'BRIEN, J. (2013) The influence of two lucerne-based forage feeds, FiberProtect ${ }^{\circledR}$ and FiberEdge ${ }^{\circledR}$ on Equine Gastric Ulcer Syndrome in horses. Journal of Applied Animal Nutrition 2

SWARM, R., ASHLEY, S., SOYBEL, D., ORDWAY, F. \& CHEUNG, L. (1987) Protective effect of exogenous phospholipid on aspirin-induced gastric mucosal injury. Am J Surg 1, 4853

TAMZALI, Y., MARGUET, C., PRIYMENKO, N. \& LYAZRHI, F. (2011) Prevalence of gastric ulcer syndrome in high-level endurance horses. Equine Vet J 43, 141-144

VATISTAS, N. J., SNYDER, J. R., CARLSON, G., JOHNSON, B., ARTHUR, R. M., THURMOND, M., ZHOU, H. \& LLOYD, K. L. (1999) Cross-sectional study of gastric ulcers of the squamous mucosa in thoroughbred racehorses. Equine Vet J Suppl, 34-39 VENNER, M., LAUFFS, S. \& DEEGEN, E. (1999) Treatment of gastric lesions in horses with pectin-lecithin complex. Equine Vet J Suppl, 91-96 